\title{
Urodimento
}

REVISTA DE ESTUDOS EM ARTES CÊNICAS

E-ISSN 2358.6958

\section{Experimentos didático-pedagógicos sobre a estética da domesticidade e a linguagem da câmera na web}

\author{
Eduardo dos Santos Andrade \\ Cristiano Cezario Rodrigues \\ Tereza Bruzzi de Carvalho
}

Para citar este artigo:

ANDRADE, Eduardo dos Santos; RODRIGUES, Cristiano Cezario; CARVALHO, Tereza Bruzzi de. Experimentos didático-pedagógicos sobre a estética da domesticidade e a linguagem da câmera na web. Urdimento - Revista de Estudos em Artes Cênicas, Florianópolis, v. 2, n. 41, set. 2021.

do) DOI: http:/dx.doi.org/10.5965/1414573102412021e0114

Este artigo passou pelo Plagiarism Detection Software | iThenticate 


\title{
Experimentos didático-pedagógicos sobre a estética da domesticidade
} e a linguagem da câmera na web

\author{
Eduardo dos Santos Andrade ${ }^{1}$ \\ Cristiano Cezario Rodrigues ${ }^{2}$ \\ Tereza Bruzzi de Carvalho ${ }^{3}$
}

\section{Resumo}

A partir de uma pesquisa prática realizada com alunos de disciplinas sobre cenografia na Universidade Federal de Minas Gerais, este artigo buscou levantar algumas reflexões sobre a adaptação e o deslocamento de determinadas práticas didático-pedagógicas ligadas ao campo da cenografia teatral para o campo da linguagem audiovisual no contexto da internet. Pretendeu-se compartilhar alguns breves exemplos de performances digitais realizadas pelos alunos, nas quais se buscou encontrar pontos de contato entre as diferentes espacialidades domésticas, para se levantar alguns questionamentos sobre a estética da domesticidade apropriada pela linguagem da câmera na internet.

Palavras-chave: Espaço cênico. Estética da domesticidade. Performance digital. Linguagem audiovisual. Práticas didático pedagógicas.

\section{Didactic-pedagogical experiments on the aesthetics of domesticity and the language of the camera on the internet}

\begin{abstract}
Based on a practical research carried out with students at the Federal University of Minas Gerais, this work aims to raise some reflections on the adaptation and displacement of certain didactic-pedagogical practices on theatrical scenography to the field of audiovisual language in the context of the internet. It is intended to share some brief examples of digital performances created by students, in which we sought to find points of contact between different domestic spatialities, and raise some questions about the aesthetics of domesticity appropriated by the language of the webcamera.
\end{abstract}

Keywords: Scenic space. Aesthetics of domesticity. Digital performance. Audiovisual language. Pedagogical didactic practices.

${ }^{1}$ Doutorado em Artes Cênicas pela Universidade Federal do Estado do Rio de Janeiro (UNIRIO) com sanduíche na Columbia University. Mestrado em Artes pela Universidade Federal de Minas Gerais (UFMG). Professor Adjunto na Escola de Belas Artes da UFMG. ednaotem@gmail.com

(9) http://lattes.cnpq.br/2225416224457420

(iD https://orcid.org/0000-0001-9239-7487

${ }^{2}$ Doutorado e mestrado pelo Programa de Pós-Graduação da Escola de Arquitetura da Universidade Federal de Minas Gerais (UFMG). Professor adjunto na Escola de Arquitetura da UFMG. cristianoarquiteto@gmail.com (9) http://lattes.cnpq.br/4557955037992266 $\quad$ (D) https://orcid.org/0000-0001-6774-7246

MRes/UL e Doutoranda na EBA na Universidade Federal de Minas Gerais (UFMG) Professora do Teatro Universitário da UFMG. terezainaciocarvalho@gmail.com

(9) http://lattes.cnpq.br/3424361161184419 $\quad$ (iD https://orcid.org/0000-0002-1685-900X 


\section{Experimentos didáctico-pedagógicos sobre la estética de la domesticidad y el lenguaje de la cámara de internet}

\section{Resumen}

A partir de una investigación práctica realizada con estudiantes de cursos sobre espacio escénico de la Universidad Federal de Minas Gerais, este trabajo tiene como objetivo plantear algunas reflexiones sobre la adaptación y desplazamiento de determinadas prácticas didáctico-pedagógicas vinculadas al campo de la escenografía teatral al campo del lenguaje audiovisual en el contexto de internet. Se pretende compartir algunos breves ejemplos de performances digitales creados por estudiantes, en los que se buscó encontrar puntos de contacto entre las diferentes espacialidades domésticas, y plantear algunas preguntas sobre la estética de la domesticidad apropiada por el lenguaje de la cámara de internet.

Palabras clave: Espacio escénico. Estética de la domesticidad. Performance digital. Lenguaje audiovisual. Prácticas didácticas pedagógicas. 
A pandemia do Coronavírus que se instalou no início de 2020 provocou uma reinvenção do fazer teatral junto a um questionamento de alguns pilares teóricos das artes da cena. Com a proibição de aglomerações de público decorrente das políticas de isolamento social, uma verdadeira corrida em direção a uma digitalização de variadas linguagens artísticas se instalou. Assistimos, como nunca antes, a uma inundação na internet de registros digitais e de experimentos online de teatro, dança, música e performance. Experiências intermediadas por telas e encontros via streaming realizados a partir de casa tornaram-se o novo normal, transformando espaços domésticos em palcos virtuais. No âmbito acadêmico, inclusive no campo das artes da cena, o impacto provocado pela pandemia da Covid 19 foi imensurável. Disciplinas de caráter prático tiveram de ser radicalmente modificadas ou canceladas. Pesquisas e procedimentos didáticos de diversas naturezas foram interrompidos ou reelaborados, dando lugar a novas reflexões teóricas e experimentos práticos. Considerado um dos maiores representantes das "artes da presença", o teatro viu alguns de seus instrumentais teóricos e pedagógicos postos em xeque.

Nesse contexto, vimo-nos confrontados com questionamentos de diversas naturezas. Se as câmeras e as telas se impõem como dispositivo estrutural dos encontros via streaming, quais seriam os lugares de convergência entre as performances digitais e a linguagem cinematográfica? Qual seria a natureza das espacialidades construídas nas performances digitais realizadas no contexto doméstico? Em que medida a estética da domesticidade tem sido apropriada como instrumento de dramaturgia? Ou, ainda, quais os impactos disso tudo nos processos de ensino e aprendizagem no campo das artes da cena?

Tomando essas questões como ponto de partida, o presente artigo tem por objetivo apresentar algumas reflexões oriundas da experiência vivida na Universidade Federal de Minas de Gerais no campo do ensino em cenografia em meio ao contexto da pandemia da Covid 19. Pretendemos compartilhar algumas questões suscitadas a partir da adaptação e do deslocamento de determinadas práticas didático-pedagógicas do campo da cenografia para experimentos realizados através da linguagem das telas da web. Junto a alguns breves exemplos 
de performances digitais realizadas pelos alunos, buscaremos levantar algumas reflexões a respeito de dois eixos que despontaram como instigantes focos de investigação: a estética da domesticidade apropriada como agente de indução dramatúrgica e a linguagem da web-câmera como ferramenta de construção espacial.

A pesquisa e o ensino sobre o espaço cênico na Universidade Federal de Minas de Gerais acontece através de disciplinas de natureza optativa e transversal ofertadas no âmbito da graduação por nós, professores pesquisadores do BARRACÃO - Núcleo de Pesquisa em Cenografia e outras práticas espaciais cênicoperformáticas ${ }^{4}$. Este núcleo desdobra-se em atividades além da pesquisa, operando também no ensino e na extensão universitária. A fundação do BARRACÃO ocorreu em 2014, quando iniciamos um experimento pedagógico ao propor a disciplina Design da Perfomance e Cenografia num formato alternativo em relação às disciplinas de cenografia ofertadas para os cursos de Teatro da UFMG (Técnico e Graduação), que eram normalmente cursadas estritamente por alunos deste campo. A proposta foi abrir a disciplina para outros cursos além do Teatro, como Arquitetura, Artes Visuais, Moda, Comunicação e outros, entendendo a natureza da cenografia em seu caráter transdisciplinar.

A cada nova edição da disciplina Design da Performance e Cenografia ${ }^{5}$, propomos um experimento prático diferente, normalmente atrelado à montagem de algum espetáculo, seja dentro ou fora da universidade. No primeiro semestre de 2020, a proposta inicial era trabalharmos junto a um espetáculo que seria montado no Palacete Dantas, uma imponente edificação no estilo eclético situada no complexo arquitetônico da Praça da Liberdade, em Belo Horizonte. A proposta

\footnotetext{
${ }^{4}$ O Barracão atualmente é um grupo de pesquisa certificado pelo CNPQ: Barracão - Núcleo de Pesquisa e Experimentação em Cenografia e outras práticas espaciais cênico-performáticas. Para maiores informações, ver <http://dgp.cnpq.br/dgp/espelhogrupo/41531> e <http://www.arq.ufmg.br/site/v2/extensao/projetos-deextensao/barracao-concepcao-e-producao-de-cenografias-no-ambito-da-ufmg/>.

5 A disciplina Design da Performance e Cenografia é semestral e é oferecida anualmente na Formação Transversal em Culturas em Movimento e Processos Criativos, com carga horária de 60h/aula e cerca de 20 estudantes. As Formações Transversais são conjuntos de atividades acadêmicas curriculares, organizadas segundo estruturas curriculares, que visam abordar temáticas de interesse geral, incentivando a formação de espírito crítico e de visão aprofundada sobre esses temas. O sistema de Formações Transversais constitui um espaço comum de formação para os estudantes de todos os cursos de graduação da UFMG. Para maiores informações: <https://www2.ufmg.br/prograd/prograd/Pro-Reitoria-deGraduacao/Estudante/Formacao-Transversal>
} 
envolveria alguns estudos teóricos em torno da noção de site specific e contaria ainda com experimentos práticos de produção e instalação de objetos que comporiam uma proposta de cenografia. Duas semanas após o início do semestre letivo, entretanto, as aulas foram interrompidas em função da implementação da política de isolamento social diante da chegada do novo Coronavírus à cidade. Um mar de dúvidas e incertezas se abria à nossa frente.

A universidade nos deu as opções de cancelar ou adaptar a disciplina a um sistema de Ensino Remoto Emergencial. Após algumas discussões e ponderações, decidimos enfrentar o desafio de ofertar a disciplina por via remota, reestruturando radicalmente as questões teórico-práticas a serem investigadas. Uma delas foi o entendimento de que a ideia de uma Cenografia mais convencional, como aquela que experimentamos no Teatro, talvez não desse conta de cobrir todas as discussões que emergiram. Nesse sentido, buscamos trabalhar com uma noção de cenografia em campo ampliado, muito próximo à ideia de design da performance, expressão que tem sido amplamente discutida em diversos fóruns pelo mundo, dentre eles, por exemplo, a Quadrienal de Praga 6 . A retomada das aulas aconteceu cerca de quatro meses após o início do confinamento, de modo que já tínhamos adquirido um determinado repertório de questões que despontavam a partir dos inúmeros experimentos de teatro e performances digitais que invadiam a internet na época. Uma dessas questões diz respeito à dicotomia da casa como um espaço simultaneamente público e privado.

Em inúmeras criações ou adaptações de teatro, shows e performances via streaming, a ideia de casa - como o lugar do íntimo, do habitat, do individual fundiu-se à ideia de cenografia, conformando uma espacialidade de natureza ambígua e complexa, na qual a dramaturgia do real se mescla à ficção, na mesma medida em que o público se confunde com o privado. Cantores, atores e artistas de gêneros diversos, como Adriana Calcanhoto, Caco Ciocler ou Denise Fraga, fizeram apresentações a partir da cama do quarto, do box do banheiro ou da bancada da cozinha, convertendo espaços de intimidade em palcos de 
apresentação pública.

Para além da dicotomia entre as noções de público e privado, a percepção da espacialidade doméstica como uma espécie de elemento constitutivo da dramaturgia despontava como uma importante questão a ser investigada. Tal questão, entretanto, é anterior à vida pandêmica, apresentando-se como uma das marcas do teatro contemporâneo. Um exemplo que nos parece bastante significativo nesse sentido é o espetáculo Domingo. Em 2014, a atriz Cida Falabella, sob a direção de Denise Pedron, desenvolveu uma cena-experiência que se passava num espaço íntimo, a casa da atriz, que abriu as portas e recebeu o público, aos domingos, para compartilhar suas vivências em forma de cena. Domingo trabalhava a luta de uma mulher pela vida, depois de uma experiência de ruptura amorosa, como uma tentativa de "desenlouquecimento", nas próprias palavras da atriz. Os ritos da sua vida vão sendo revividos pela atriz desde o quintal da casa até a cozinha, estabelecendo um ritmo entre os espaços da casa com a narrativa e compartilhados com o pequeno público que se misturava ao espaço doméstico. Viver a casa é sentir a própria vida da artista como se não houvesse separação entre casa, corpo e história.

A experiência doméstica proposta em Domingo, com seu compartilhamento de um rito-cena, vai ao encontro de inúmeros experimentos realizados via streaming no contexto pandêmico. Em algumas adaptações de espetáculos teatrais, concebidos e estreados antes mesmo da pandemia e remontados nas casas dos artistas, a intimidade do espaço doméstico parecia impor uma nova camada de sentido, potencializando, por vezes, questões centrais da dramaturgia do espetáculo. Tomemos como exemplo o espetáculo Desconscerto, solo do ator Matheus Nachtergaele, apresentado a partir da sala de sua casa. O trabalho foi uma adaptação da peça Processo de Concerto do Desejo, dirigida por Miriam Juvino, na qual o ator, num palco quase nu, recita poemas de sua mãe, Maria Cecília Nachtergaele, que se suicidou aos 22 anos, quando ele possuía apenas três meses de idade, em 1968. Na versão para web, os móveis clássicos, os tons sépia e os detalhes sóbrios da decoração da casa de Nachtergaele realizam uma delicada tessitura com o texto declamado. No sofisticado jogo de planos e profundidades realizado pela câmera, o espaço e seus objetos entram num diálogo 
profundo com os poemas, revelando uma dimensão interior tanto do personagem quanto do ator, que expõe sua própria história.

Se Desconscerto ganhou novas camadas de sentido a partir de sua adaptação e recriação na casa do ator, em diversos experimentos originariamente concebidos no contexto do isolamento social, o espaço doméstico já se oferecia como força motriz do impulso criativo. Este foi o caso da performance Ensaios do corpo no lugar de morar, de Natalia Barros, experimento que compôs seu Trabalho de Conclusão de Curso em Arquitetura e Urbanismo. A performance apropria-se do espaço da casa e estabelece um diálogo entre o corpo e sala de televisão, buscando subverter tensões do cotidiano e do habitar ordinário, imprimindo um outro modo de apropriação do espaço, mais imaginativo e contestador. A performance foi transmitida via streaminge tinha como principal mote a discussão da domesticidade nos tempos pandêmicos, entendendo-a a partir de duas perspectivas, a do doméstico, ou seja, aquilo que assume o sentido da vida em casa, bem como a de domesticar, enquanto estado de sujeição do ser. Questionava-se o quanto a arquitetura e seu espaço imporiam um determinado modo de viver, onde os constrangimentos dos usos cotidianos seriam um projeto de controle dos corpos em diversas escalas, desde o privado da casa ao público da cidade.

Em Processo de Conserto do Desejo, Domingo e Ensaios do corpo no lugar de morar, a memória, o corpo e a criação parecem estabelecer uma conexão com o espaço da ordem do autobiográfico. Nesse sentido, a domesticidade inscrita nesses espaços é a identidade autobiográfica que se reflete na escolha dos objetos, fotos, móveis, cores e formas do espaço doméstico. Se já sabíamos, mesmo antes da pandemia, da potência do espaço doméstico, potencializador do ator como um sujeito de uma narrativa pessoal, nesse momento em que todos precisávamos ficar em casa, pareceu-nos rico e importante a exploração de tal tema.

A partir dessas percepções, estruturamos uma linha de investigação teóricoprática para a disciplina. Após um período de discussões e reflexões sobre questões que atravessam as noções de espaço cênico, design da performance, teatro e internet, propusemos uma experimentação prática dessa cenografia 
pandêmica a partir da investigação da performance da casa, da poética do íntimo, da estética da domesticidade. A ideia era buscar encontrar a dramaturgia da casa como o lugar do habitar - entendendo o habitar como uma performance do cotidiano e uma culminação física do corpo no espaço que estabelecesse um cunho biográfico. Habitamos a casa com o nosso corpo e criamos no corpo habitual memórias desse "habitar" e da familiaridade desse lugar. E é justamente nessas memórias corporais, nos hábitos e nos movimentos repetidos e restaurados do cotidiano, que o espaço nos performa, manifestando uma espécie de dramaturgia implícita nas superfícies, formas e design dos ambientes, móveis e objetos.

O objetivo do trabalho era explorar essa dramaturgia, investigando o design da performance da casa através da realização de um vídeo. Os trabalhos deveriam ser individuais, e os alunos deveriam gravar o vídeo com o próprio celular, com ou sem edição, tendo duração máxima de 5 minutos. Determinamos que o quarto, o banheiro e a cozinha seriam lugares considerados essenciais na constituição do "habitar", ainda que esses lugares estivessem reunidos num único espaço. Assim, o estudante deveria escolher pelo menos um desses três espaços para realizar a performance, sendo facultativo a experimentação em outros espaços da casa. Determinamos também que o espaço deveria ser filmado vazio - ou seja, antes ou depois de ocupar o espaço, o aluno deveria explorar ou apresentar aquele ambiente desocupado.

Para refinar e orientar melhor o processo criativo, enviamos várias recomendações e sugestões. A performance poderia contemplar diversas formas de ação no espaço, subvertendo ou reiterando seu uso, através da repetição de movimentos do cotidiano, ou da realização de uma dança, etc. Os alunos poderiam eleger um objeto ou um móvel como símbolo do espaço, executando ações e movimentos relacionando-se com ele, podendo-se explorar detalhes ou o conjunto dos ambientes, utilizar câmera parada ou em movimento, textos ou músicas.

A ideia de se eleger a cozinha, o banheiro ou o quarto como ambiente preferencial para a realização do vídeo-performance teve como motivação o desejo de construção de uma obra única como um possível desdobramento 
futuro. Ao final da disciplina, teríamos um acervo de vídeos com ações realizadas em diversos banheiros, cozinhas e quartos - um material bruto a ser investigado e explorado, podendo ser convertido num trabalho único através de operações de edição e montagem. A possibilidade de se agrupar diversos banheiros, cozinhas e quartos segundo uma determinada linha dramatúrgica apontava para um caminho promissor no processo de investigação do tema da estética da domesticidade. A questão dos recursos de montagem e de edição, entretanto, apresentava-se como um desafio a ser enfrentado por todos nós - alunos e professores. Conscientes de que muitos estudantes poderiam ter dificuldades técnicas nessa tarefa, tanto pela falta de familiaridade com o uso de ferramentas digitais quanto pela ausência de dispositivos adequados, deixamos claro para os alunos que a realização do trabalho não exigiria nenhum tipo de montagem - ou seja, os vídeos poderiam ser gravados sem cortes ou edição, num único plano-sequência, através da câmera do celular. Cabia ao estudante a decisão de pesquisar e experimentar, por conta própria, recursos de edição e montagem.

Dos diversos trabalhos desenvolvidos na disciplina, apresentaremos três que consideramos uma amostra mais significativa. Mariana Teixeira (Fig. 1) escolheu o banheiro como local de desenvolvimento do seu trabalho. O trabalho é atravessado por uma questão plástica, quase pictórica, materializando-se como um elaborado jogo de contraste de cores entre as louças sanitárias e os azulejos do ambiente. Sua escolha por planos em close mostra os objetos e o seu corpo de maneira quase invasiva, uma vez que nada é visto inteiramente, tornando a relação intensa e forte. O corpo feminino e o espaço do banheiro formam um caleidoscópio de fragmentos que dialogam, performando entre si por meio das imagens e dos sutis movimentos dos líquidos que os atravessam. A trilha sonora também opera como uma outra camada de coesão no trabalho do início ao fim. O íntimo, característico do doméstico, chega a ser visceral na performance e a linguagem utilizada no vídeo potencializa ainda mais essa invasão do espectador diante do trabalho. 

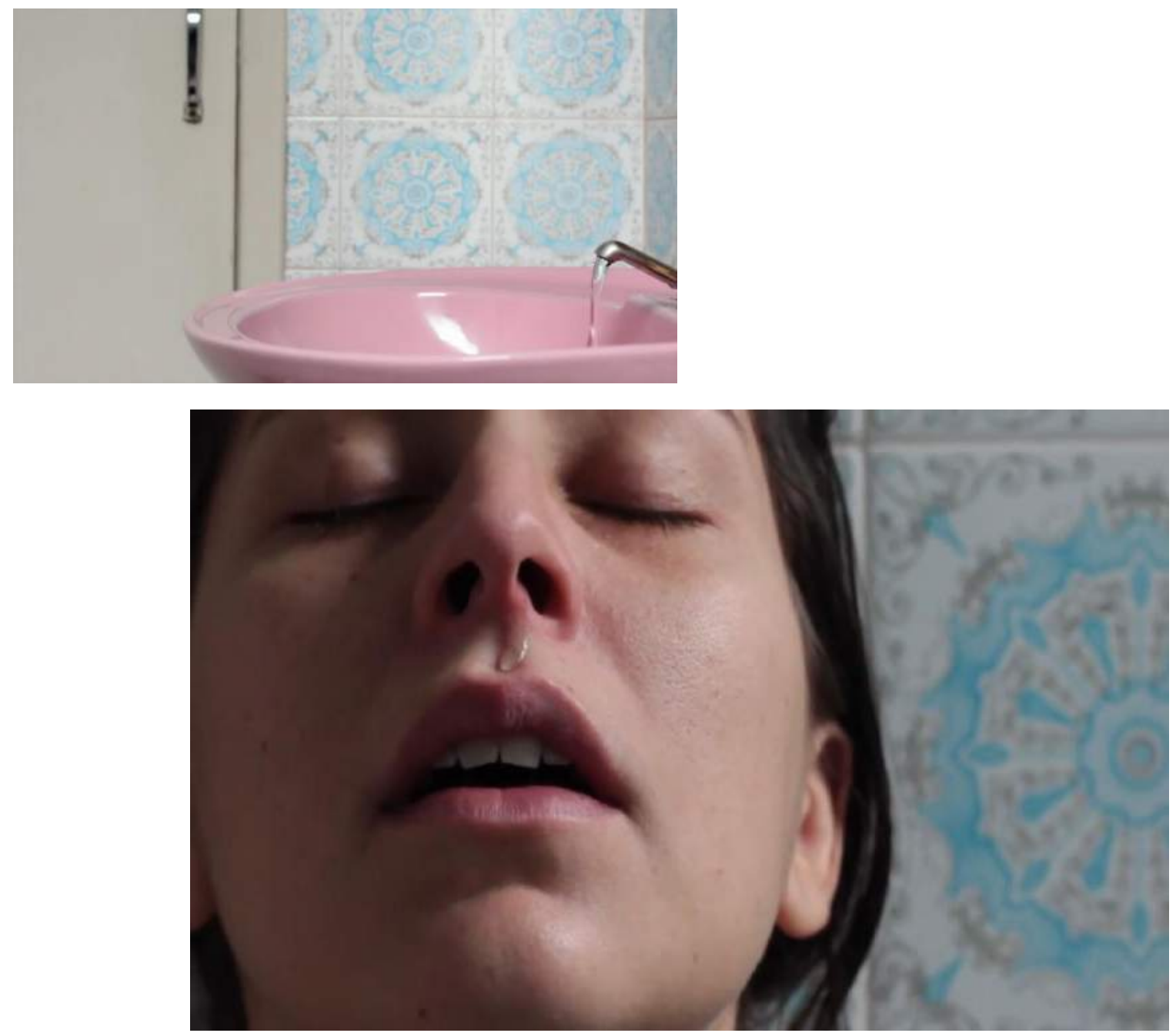

Acervo da disciplina Design da Performance Link para o vídeo: https://www.youtube.com/watch?v=GY4frm8hR5E

Bruno Gusmanini, no trabalho Expectativa x Realidade (Figura 2), escolheu a cozinha como espaço de investigação. Trabalhando com a câmera estática, ele coloca a cena em três planos: o primeiro corresponde à bancada da cozinha onde, junto a garrafas de cerveja e outros objetos, está a tela do computador com a imagem de uma praia; o segundo é a área da cozinha propriamente dita; e o terceiro, mais ao fundo, é a área externa onde o performer se refresca com um ventilador e uma mangueira. Construídos a partir dos objetos e do espaço, os planos de profundidade permitem uma narrativa irônica e divertida. As situações 
criadas no plano de fundo são emolduradas pelas aberturas existentes na própria arquitetura do espaço - janela e porta - estabelecendo um jogo de quadros que se apresenta como uma metáfora conflituosa entre a expectativa, quase utópica nos tempos pandêmicos, e a realidade imposta pela vivência cotidiana.

Figura 2 - Expectativa x Realidade, de Bruno Gusmanini

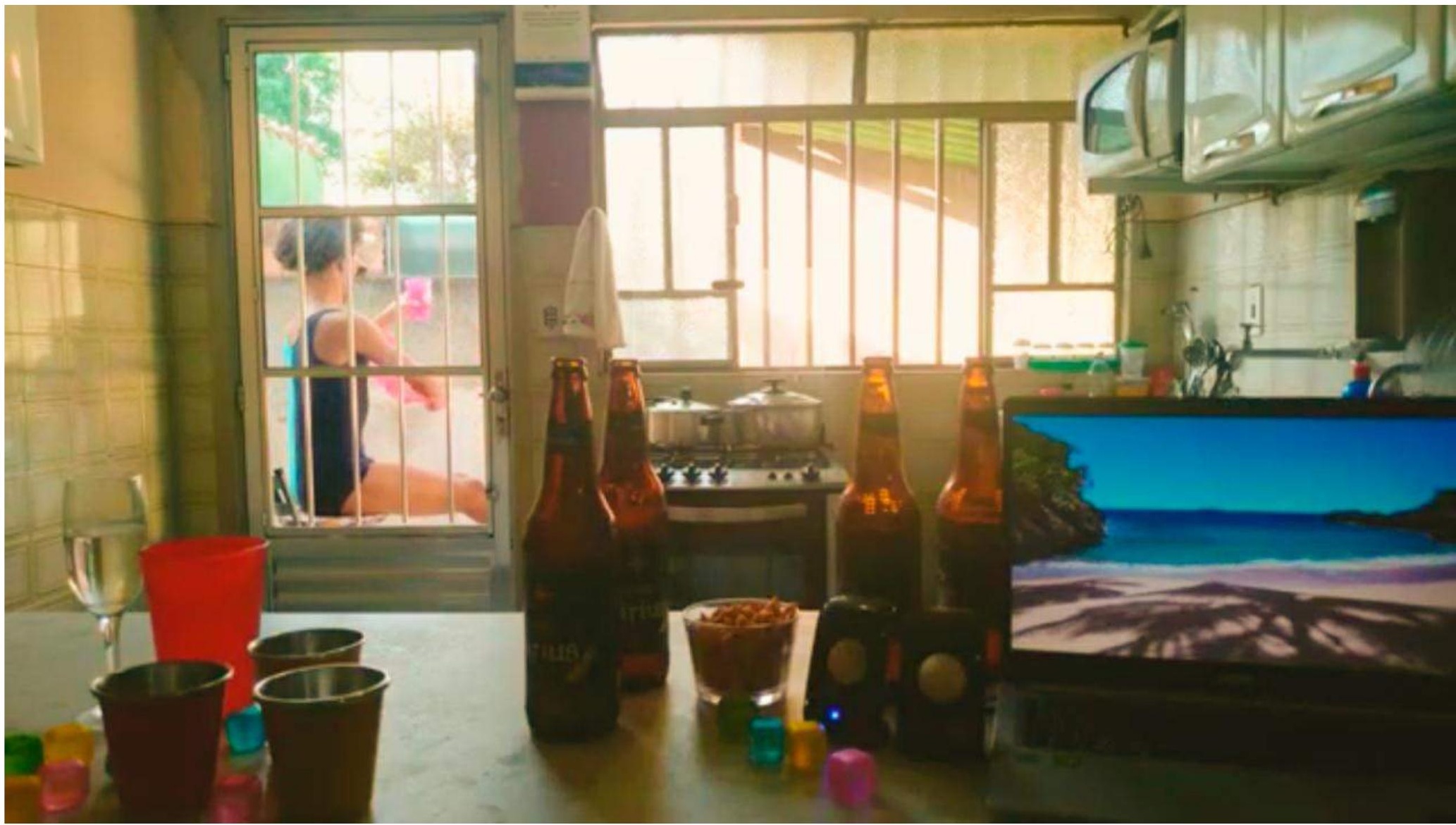

Acervo da disciplina Design da Performance

Link para o vídeo: https://youtu.be/6s6mJ3t-zco

No caso do trabalho de Lucas Raimundo (Luba) (Figura 3), intitulado Traduttore Traditore, ele utiliza a casa como um todo, ocupando boa parte dos espaços. O trabalho opera num ritmo crescente no qual os espaços são inicialmente apresentados vazios, para em seguida serem ocupados pela presença do performer, que se multiplica através de recursos de colagens e superposições realizadas com recursos de edição de vídeo. Com uso de câmera estática e cortes secos, essa sequência de imagens vai criando uma narrativa complexa do espaço, 
tendo o doméstico como pano de fundo. Outro recurso utilizado é a narração oral em uma língua imaginária, que é incompreensível, mas que soa familiar, associada a legendas em diversos idiomas, provocando um estranhamento ao longo de todo o trabalho. Com um sofisticado trabalho de edição, as imagens geradas criam jogos de presença e multiplicidade, construindo uma relação dinâmica e complexa entre corpo, espaço e objetos.

Figura 3 - Traduttore Traditore, de Luba
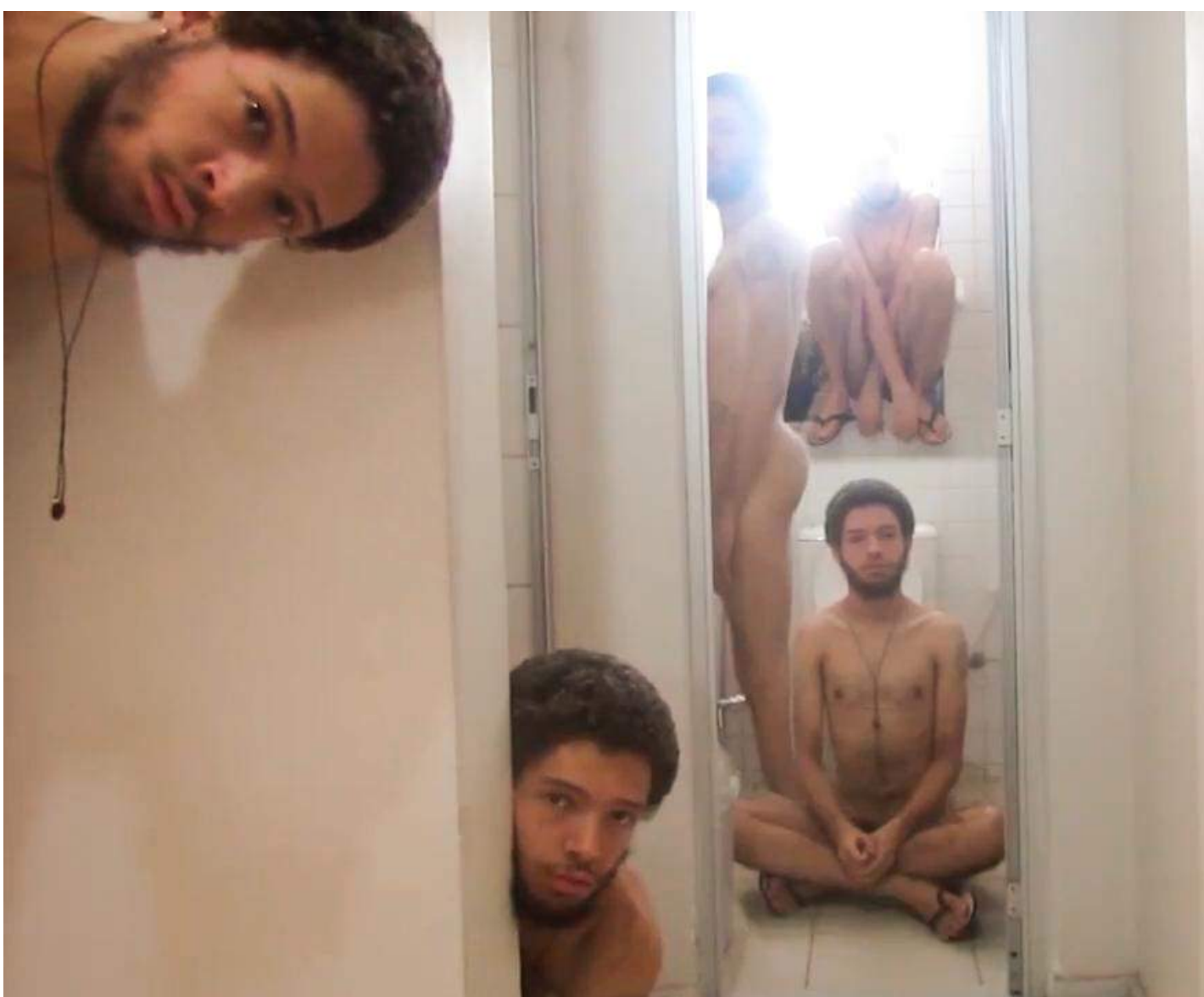

Fonte: acervo da disciplina Design da Performance Link para o vídeo: https://youtu.be/w2fxemdfpnw

O sucesso da experiência proporcionada pela disciplina, verificado na qualidade dos trabalhos finais e sobretudo nas reflexões levantadas ao longo do processo, nos levou a dar continuidade à pesquisa. No segundo semestre letivo de 2020, cujo início foi no mês de dezembro, demos continuidade a essa experiência através de duas frentes: a formatura dos alunos do curso técnico do Teatro 
Universitário (T.U.) e a oferta de duas outras disciplinas no âmbito da graduação, em formato concentrado, abarcando temas que, de certa forma, pareciam despontar como desdobramentos "naturais” do percurso de investigação.

A disciplina de formatura do curso técnico em teatro do T.U. colocou, desde o início, a questão do espaço doméstico como um lugar norteador para as pesquisas. Como estratégia didático-pedagógica, optamos por desenvolver um storyboard de cada cena, tentando construir sentido a partir do olhar da câmera e oferecer uma experiência estética alinhada à linguagem da internet. Tomando o espaço doméstico como um local de memória e afeto, a ideia era investigar como os espaços da casa (internos e externos) poderiam gerar uma pulsão dramatúrgica, com efeitos de vida, de forma a potencializar o habitar e fazer emergir uma autobiografia em cada cena. Os alunos deveriam ganhar autonomia a partir desses trabalhos.

Como exemplo dessa experiência, trazemos o trabalho Portas que dão para dentro, de Bianca Freire (Figura 4). Partindo do conto O Edifício, de Murilo Rubião, a atriz inicia sua investigação no próprio edifício onde mora, localizado na área central de Belo Horizonte. Além do conto, a criação também teve como mote uma carta que demonstra a saudade a um amigo. Embora o trabalho se apoie numa matriz literária, a força do espaço na constituição da dramaturgia aparece de maneira muito clara na cena. A câmera assume uma função de observação direta em planos sequência, colocando-nos ali, na casa da atriz, apresentando-nos quem ela é, expondo sua intimidade em três espaços distintos - o quarto, a sala e a cozinha. Em seguida, inicia-se um diálogo com o mundo externo, através das janelas e varandas do apartamento, abrindo a relação da protagonista com o exterior por meio de colagens que irão traduzir uma visão crítica sobre a sociedade e o comportamento humano. Numa sequência final, a atriz parece ir ao encontro dos seus sentimentos mais puros e, num certo sentido, amorfos. O lugar escolhido é o corredor, um "não-lugar", oferecido à circulação, e não à permanência. Nesse sentido, as funções dos espaços parecem determinar os sentimentos, ou viceversa, sugerindo camadas e profundidades da narrativa. 
pedagógica desenhada a partir de diversas reflexões extraídas da primeira experiência na Formação Transversal. Diante da imposição das câmeras e das telas como dispositivo estrutural nos experimentos realizados, a investigação dos lugares de convergência entre as performances digitais e a linguagem cinematográfica parecia emergir como um importante objeto de estudo. Para além do tema da estética da domesticidade, que serviu como alicerce para a criação dramatúrgica, o que se observava nas reflexões a respeito dos experimentos realizados eram discussões sobre a sofisticação da edição e da montagem, a potência dos enquadramentos ou a dinâmica dos movimentos de câmera na constituição da poética daqueles trabalhos. O poder da câmera se impunha como ferramenta de escrita, remetendo a alguns fundamentos da linguagem cinematográfica. Assim, como estratégia pedagógica, pareceu-nos necessário voltar às origens daquilo que deu à luz o arcabouço teórico da linguagem audiovisual para então retomar e avançar nas investigações junto aos experimentos na web.

Ofertada como optativa para estudantes do Curso de Graduação em Teatro, com carga horária de 60 horas/aula, a disciplina Estudos de Cinema e suas Interfaces com Teatro teve uma grande procura, revelando um forte interesse dos alunos pelos temas do cinema e dos fundamentos da linguagem audiovisual. Diferentemente de sua predecessora e de sua sucessora nesse processo investigativo, a disciplina possuiu um caráter eminentemente teórico, tendo como metodologia leitura de textos, exibição de filmes e seminários temáticos com discussões sobre o cinema em seu momento inaugural, sobre algumas das principais correntes estilísticas da história da sétima arte e sobre algumas produções contemporâneas, destacando-se aspectos técnicos e estéticos. Princípios básicos sobre as teorias do cinema foram investigados, como as funções do movimento de câmeraª, capazes de imprimir ritmo e gerar tensionamento, ou o Efeito Kuleshov , fundado nas relações entre as imagens, ou na própria ideia de

Dentre as principais funções da câmera identificadas por Marcel Martin (2003) estão: a Função descritiva (acompanhamento de um personagem ou de um objeto em movimento, descrevendo um espaço uma ação); a Função dramática (definição de relação espacial entre dois elementos da ação); e a Função rítmica (mobilidade da câmera criando uma dinamização do espaço, que se torna fluido e vivo).

${ }^{8}$ O Efeito Kuleshov refere-se a um famoso experimento realizado pelo russo Lev Kuleshov para demonstrar o poder da montagem no cinema. Kuleshov combinou uma sequência de imagens apresentando um rosto 
montagem - noção fundamental da linguagem cinematográfica, conforme teorizado pelo grupo que compunha o famoso Cinema Soviético.

Além disso, a disciplina pautou-se sempre pela reflexão sobre os limiares e fronteiras entre o cinema e o teatro, investigando especificidades das duas linguagens, o que nos levou a uma espécie de inversão do polo de discussão, deslocando-o das produções cinematográficas para as obras cênicoperformáticas que se apropriam fortemente de aspectos técnicos e estéticos do cinema, a exemplo dos trabalhos da carioca Christiane Jatahy e do norteamericano The Wooster Group. Assim, com a realização dessa disciplina, buscouse criar, para além de um arcabouço teórico, uma sensibilização do olhar dos alunos para algumas das questões fundantes da linguagem audiovisual e suas fronteiras com princípios das artes da cena.

Já a disciplina seguinte, O Espaço Digital da Performance: Cenografia, Teatro e Internet ${ }^{9}$, retoma uma proposta de natureza teórico-prática, adotando-se como metodologia leitura de textos, análise de vídeos, pesquisa de referências e realização de experimentos práticos coletivos de performances digitais. Tomando sempre a linguagem cênico-performática como força motriz do processo criativo, a disciplina buscou, fundamentalmente, atualizar algumas questões levantadas a respeito da linguagem audiovisual, problematizando seu funcionamento junto à estética da web. Uma vez que a questão espacial é o tema central do nosso grupo de pesquisa, vale destacar que alguns aspectos teóricos foram frequentemente abordados a partir da perspectiva do espaço, buscando-se compreender a câmera como agente de construção de espacialidade ${ }^{10}$.

Para além das questões de movimento de câmera, enquadramento, corte, edição e montagem suscitadas pelos experimentos práticos realizados na disciplina sobre Design da Performance e investigados como objeto teórico na

sem expressões intercalado com imagens de naturezas diferentes que tenham significado para o espectador, como um prato de sopa, seguida pela imagem de uma criança dentro de um caixão e, em seguida, a de uma mulher num sofá. A impressão que se cria é a de que o rosto exibido entre as apresentações dessas três imagens têm expressões diferentes a cada momento, mas na verdade a imagem do rosto é a mesma. Essa percepção se deve à nossa interpretação da cena apresentada.

${ }^{9}$ A disciplina foi realizada com 16 estudantes e teve carga horária total de 45 horas/aula.

10 Segundo Stephen Heath (apud Aumont, 2004), o cinema constrói e manipula o espaço ao longo do desenvolvimento da narrativa, transformando-o em espaço de representação através de três movimentos distintos: o movimento dos personagens; o movimento da câmera; o movimento de uma tomada para outra. 
disciplina Estudos de Cinema, o que se buscou aqui foi compreender novas estratégias de combinação de imagens operando em favor da produção de sentido, através da experimentação do uso de telas múltiplas simultâneas que frequentemente compõem a estética da internet. Desse modo, o processo de investigação avançava, almejando não mais a realização de vídeo-performances digitais individuais, mas a produção de uma obra de caráter coletivo que ultrapassasse o tradicional formato de montagem linear originário do cinema, pautado na lógica da tela única.

Para esse objetivo, a realização do trabalho prático foi a principal ferramenta de investigação. Foi proposto aos alunos a realização de um vídeo, em grupo, explorando a articulação de imagens como recurso narrativo, de modo a se investigar uma construção poética própria da linguagem da internet. Semelhante ao que foi proposto como experimento prático na primeira disciplina, Design da Perfomance, a estética da domesticidade, ou a espacialidade da casa, foi tomada como ponto de partida do processo criativo. A diferença fundamental estava no caráter coletivo proposto para este trabalho: caberia agora conectar as diferentes estéticas domésticas dos integrantes do grupo. O tema proposto para provocar essas conexões foi o desejo de se encontrar o outro. Partimos da reflexão de que, com o arrastar dos vários meses de isolamento, junto à iminente chegada da sonhada vacina, o desejo e a expectativa pela possibilidade de encontros e de trocas pareciam se potencializar. Entretanto, todos ainda precisamos nos manter recolhidos em nossas casas. O tema para a realização do trabalho foi, portanto, 0 desejo de conexão com o outro (bem como "do individual ao coletivo", ou do "dentro para fora"), a partir da estética da domesticidade. A ideia era buscar encontrar pontes possíveis entre o mundo interior de cada um, metaforizado na espacialidade íntima da casa, e o mundo do outro. Sugerimos, assim, explorar o cruzamento de diferentes familiaridades de lugar, diferentes memórias corporais do habitar, diferentes manifestações de movimentos cotidianos repetidos e restaurados nos ambientes, móveis e objetos de cada integrante do grupo, a fim de se costurar uma espécie de dramaturgia pandêmica, alinhada à estética da web.

Algumas perguntas foram postas como provocações e estímulos: Como é possível nos conectarmos espacial e corporalmente estando cada um em sua 
casa? Quais os pontos de contato entre as diferentes espacialidades domésticas de cada um? Como expressar um desejo de conexão com o outro e com o mundo exterior? É possível identificar uma dramaturgia comum a diferentes estéticas de domesticidade? Como construir sentido e oferecer uma experiência estética a partir da articulação de imagens dentro da linguagem da internet?

Novamente, os alunos deveriam realizar um vídeo pelo celular, porém, desta vez, produzido por grupos de até cinco alunos, com duração máxima de 10 minutos. O trabalho de compilação, edição e montagem seria, portanto, fundamental, já que cada aluno estaria produzindo as imagens a partir de sua casa. De acordo com as orientações fornecidas, os alunos poderiam escolher qualquer espaço da casa, inclusive ambientes externos, desde que o espaço doméstico participasse ativamente da dramaturgia, em contraponto ou em complemento aos espaços exteriores. Foi sugerida, ainda, a possibilidade de se trabalhar a partir da ideia de dicotomias e contrastes, como dentro x fora; individual x coletivo; grande $x$ pequeno.

Os experimentos exploraram temas e estéticas bastante variadas. Um dos grupos, composto por quatro alunas ${ }^{11}$, elegeu uma mesa de café da manhã como espaço de investigação, buscando imprimir um sentido de continuidade às ações realizadas em diferentes casas. Construído a partir de um roteiro de caráter ficcional, o trabalho Tea, ou qual delas estava certa explora uma estética própria do mundo da internet, ironizando o comportamento crítico e a submissão ao julgamento da rede através da simulação de interações das personagens com supostos comentários de internautas. Já o trabalho Janelas de memórias (Figura 5) explora a dicotomia interior versus exterior a partir da apropriação da janela como uma metáfora física e espacial de um desejo de conexão com outro. Criado por cinco estudantes ${ }^{12}$, o trabalho experimenta o uso de telas múltiplas, num jogo de edição em que os olhares para o mundo exterior, enquadrados por janelas de diferentes formatos, a partir de diferentes casas, pareciam expressar uma mesma mistura de angústia e esperança, alento e solidão.

${ }^{11}$ Barbara Martins, Giovanna Bettio, Livia Rabelo e Mariana Vilefort

${ }^{12}$ Ellen Araújo, Gabriela Fernanda, João Vitor, Maisa do Carmo e Wily Leite 


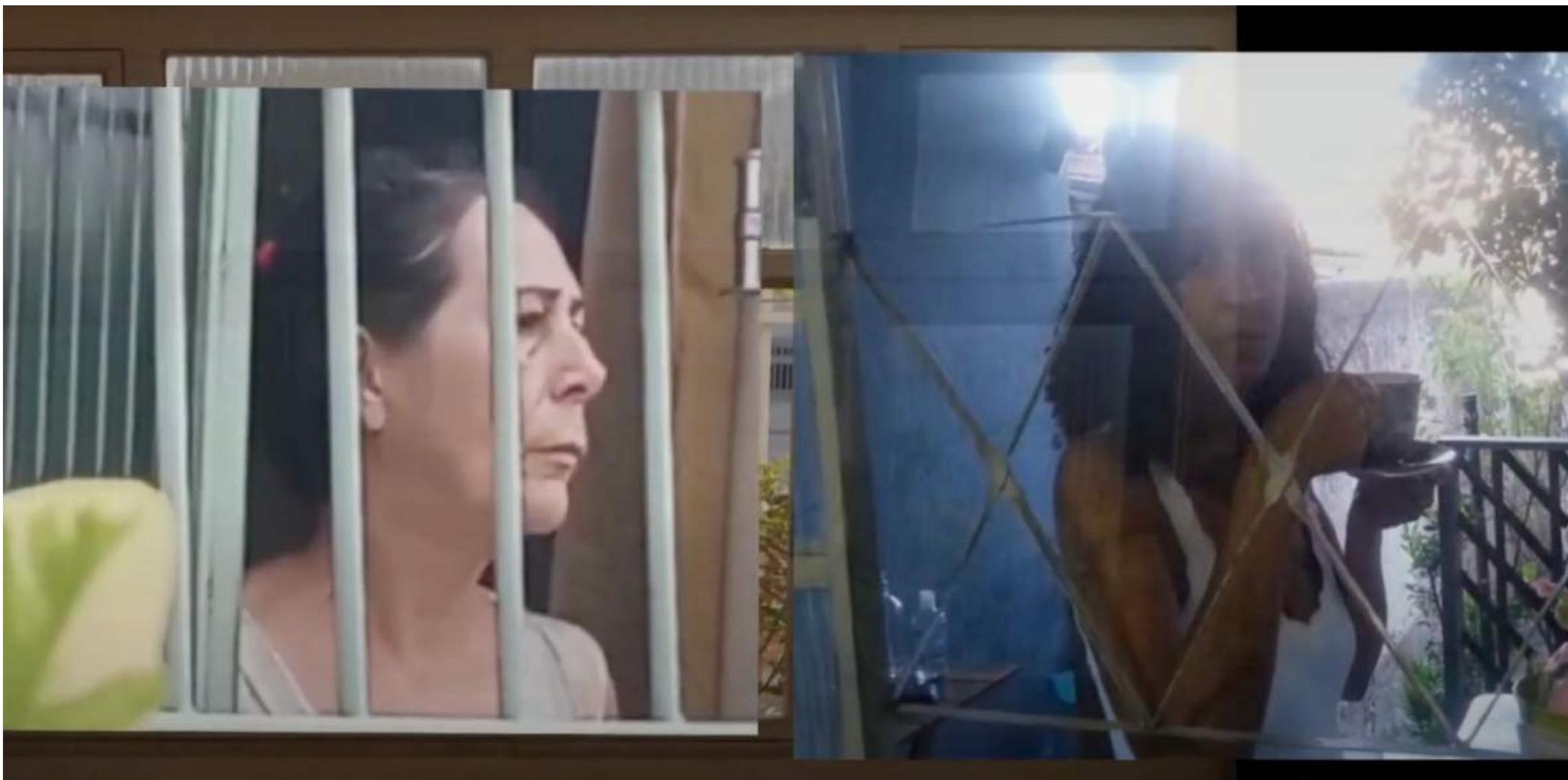

Acervo da disciplina $O$ espaço digital da performance Link para o vídeo: https://www.youtube.com/watch?v=VqK250s2Swo

No trabalho Vai ficar tudo bem na medida do (im)possível (Figura 6), a experimentação com o uso de telas múltiplas complexifica-se. Composto por quatro estudantes $^{13}$, o grupo investe nas possibilidades narrativas a partir de estratégias de colagens e multiplicação de imagens, rompendo de forma mais radical com a lógica de montagem tradicional da linguagem audiovisual estabelecida junto às origens do cinema. Assim como nos outros trabalhos, os alunos realizavam ações cotidianas em espaços domésticos, como banheiros, corredores e escadas, explorando jogos de planos e profundidades. Porém, em determinados momentos, o trabalho de edição, realizado através de um sofisticado efeito de multiplicação de imagens, potencializa de forma radical a ação filmada: na cena do grito, subitamente, o som alto que se ouve a voz das performers é silenciado, enquanto seus rostos são multiplicados

${ }^{13}$ Adelia Nazario, Adelita Siqueira, Samuel Moreira e Sinara Teles 
exponencialmente, fazendo com que aquele berro, desesperado e silencioso, ecoe para o mundo todo. Em outro momento, o trabalho de colagem realizado a partir de diferentes partes dos rostos dos alunos parece resgatar uma estética dadaísta como uma espécie de manifesto sobre uma inescapável loucura coletiva.

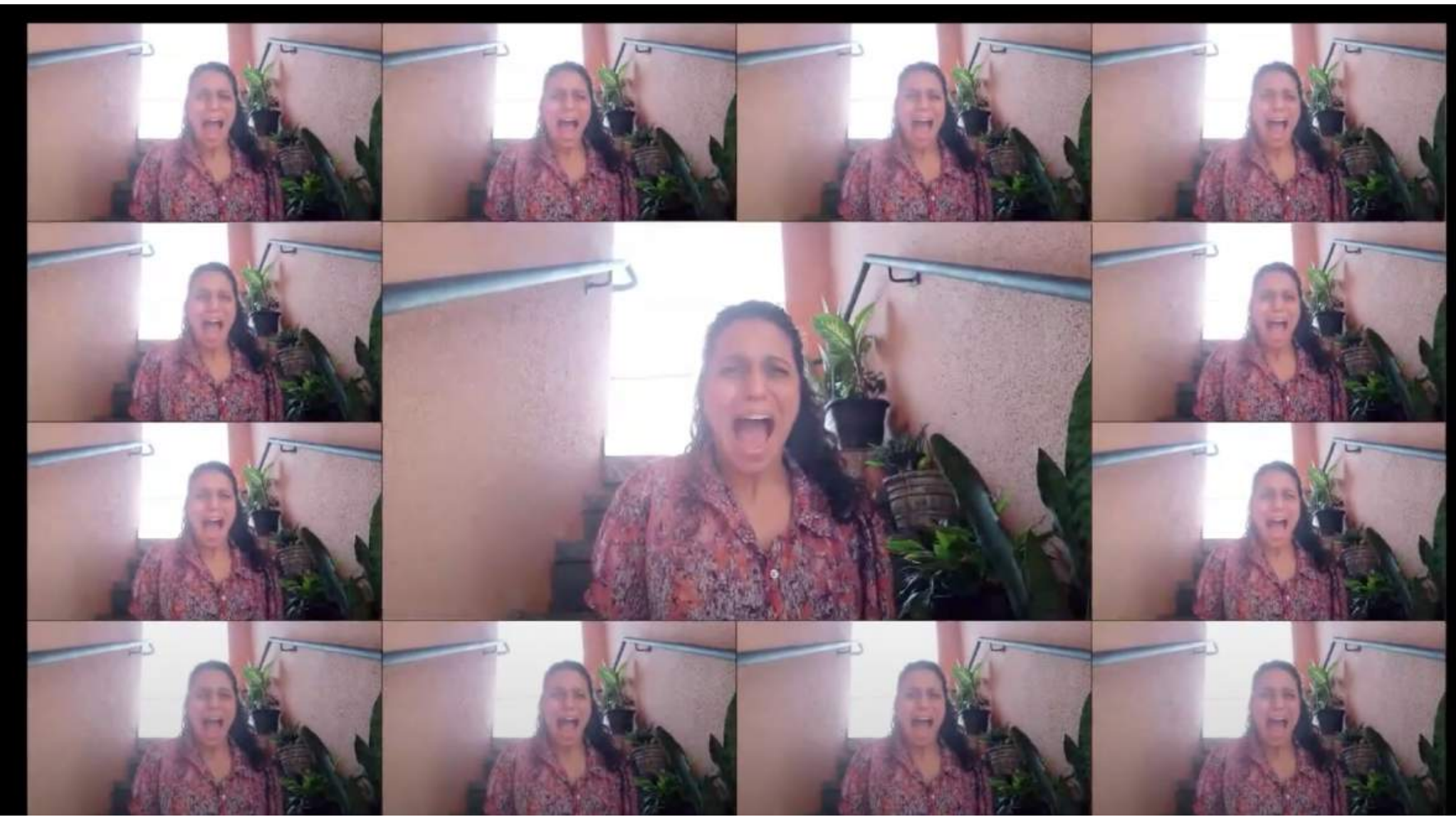

Acervo da disciplina $O$ espaço digital da performance

Link para o vídeo: https://www.youtube.com/watch?v=VqK250s2Swo

Por fim, como último exemplo desta disciplina, a obra E se o trabalho doméstico fosse remunerado?, realizada por um grupo de duas alunas ${ }^{14}$, explora o tema do trabalho doméstico, colocando em questão o fato de que as atividades domésticas têm sido não apenas atribuídas às mulheres, como também se transformado em um atributo natural da psique e da personalidade femininas. "No intuito de contrastar a normalização da invisibilidade dos afazeres domésticos,

${ }^{14}$ Marcia Weyh e Vitória Viviani 
performamos, para reforçar e expressar os desprazeres em se trabalhar de graça, sem alternativa de retorno", diz o texto de apresentação do trabalho. Inspirada pela frase "nossos rostos se tornam distorcidos de tanto sorrir", do livro de Silvia Federici (2019), Marcia Weyh cria, em sua casa, uma atmosfera de sentimentos ao realizar um dos maçantes afazeres do lar: estender e recolher roupas sujas. A alguns quilômetros de distância, Vitória Viviani "ressoa mulheres que se sufocam com o grito não dado em seus próprios lares, procurando diálogo ao lavar a louça”, conforme o depoimento da própria aluna. A partir da linguagem da videoperformance, a edição intercala e sobrepõe as imagens dos movimentos restaurados das performances do cotidiano das duas mulheres, numa tentativa de se descobrir o que está recôndito no interior da estética da domesticidade.

Devido ao seu caráter de criação coletiva, os experimentos realizados nesta disciplina revelaram um grau de dificuldade ainda maior, na medida em que demandavam uma organização e um alinhamento dos diferentes desejos e das diferentes proposições criativas dos componentes do grupo. De certa forma, aquele estudante que assumia o trabalho de edição exercia enorme influência sobre o resultado final do experimento. Mas, do ponto de vista da apropriação da estética da domesticidade pela linguagem audiovisual da web, as reflexões extraídas desta disciplina vão ao encontro de reflexões levantadas também na disciplina de montagem do TU e na disciplina de Design da performance, ponto de partida deste processo investigativo. Como fechamento deste artigo, apresentamos a seguir algumas breves conclusões, organizadas em três eixos: a estética da domesticidade como agente de dramaturgia, a linguagem audiovisual no contexto da internet e, por fim, reflexões sobre questões pedagógicas e desdobramentos futuros.

A estética da domesticidade verificada na web aponta para alguns preceitos fundamentais da cena contemporânea, sobretudo no que diz respeito ao teatro performativo, que tem no espaço um de seus principais pilares. Diversas práticas cênico-performáticas atuais frequentemente adotam o espaço como agente operador na constituição do sentido global da obra. Essa operação pauta-se numa dicotomia real versus ficcional, através da qual espaços reais fundamentam a construção da dramaturgia. No exemplo citado do espetáculo Domingo, de Cida 
Falabella, realizado antes do contexto da pandemia, a casa da atriz apresenta-se como um agente performativo, proporcionando aos espectadores uma experiência espacial capaz de ampliar a dramaturgia autobiográfica textual. De modo semelhante, em Desconscerto, de Matheus Nachtergaele, a casa do ator exibida pelas telas, ao apresentar para o público a intimidade do artista, impõe-se como uma nova camada de sentido, potencializando a própria essência do texto. Ou seja, do mesmo modo que o espaço das locações reais, com sua "carga de realidade", influencia ou até mesmo determina um eixo dramatúrgico nas práticas cênicoperformáticas "presenciais", os espaços íntimos das casas das pessoas, revelados e exibidos virtualmente nas redes, são oferecidos como uma poderosa camada de leitura a ser incorporada e absorvida pela dramaturgia. Entretanto, ao tomarmos as práticas performáticas virtuais como objeto de investigação, podemos nos perguntar: em que medida o potencial de visualização e de viralização das imagens nas redes recoloca ou redimensiona essa ideia do espaço vivido, espaço habitado, como um espaço de intimidade? Ou, ainda, haveria uma desestabilização da relação entre o público e o privado? Essas são algumas questões que, assim nos parece, despontam como temas de investigações futuras.

Um segundo tópico que merece ser destacado como um eixo de reflexão diz respeito ao poder da câmera e das telas nas experiências investigadas, o que nos leva a identificar algumas especificidades da estética da internet enquanto prática audiovisual. Se a linguagem cinematográfica fundamenta alguns princípios operadores da linguagem audiovisual da web, esta apresenta características próprias, com seus códigos específicos e sua lógica particular. O tamanho e o formato das telas no contexto da internet, por exemplo, proporcionam uma experiência totalmente diferente da cinematográfica. Pensadas para serem exibidas na telona da sala escura do cinema, as imagens cinematográficas lançam mão de complexas estratégias narrativas e de composição de imagem, que, muitas vezes, não são "exportáveis" para a estética das redes. As telas pequenas dos celulares parecem privilegiar a leitura de planos detalhe ou de planos médios, preferencialmente de curta duração, enquanto as generosas dimensões da imagem cinematográfica permitem um jogo de enquadramentos e de movimentos de câmera mais sofisticado, oferecido à contemplação. Além disso, o frequente 
uso de telas múltiplas e simultâneas, característico do mundo da internet, parece seguir uma outra lógica de narrativa visual, ao mesmo tempo em que constrói diferentes relações de espacialidades. São telas que estão muito inseridas no nosso contexto doméstico, sendo atravessadas pelas atividades cotidianas, de modo que a contaminação do ambiente na tela acaba por influir na maneira como interagimos com ela. Trata-se de uma estética que, em larga medida, reflete a própria experiência do mundo contemporâneo: um mundo mediado por telas, a ser lido e interpretado através de imagens rápidas, múltiplas e simultâneas. Se essa estética já está consolidada na vivência cotidiana, ela se mostra um campo de investigação frutífero a ser explorado em âmbito acadêmico, sobretudo no que tange ao design da performance e a cenografia, o que impôs um desafio ainda maior aos experimentos realizados do ponto de vista didático.

Por fim, como terceiro eixo de reflexão, apontamos algumas questões pedagógicas suscitadas ao longo dessa experiência investigativa. Primeiramente, é preciso destacar a dificuldade encontrada para se conduzir processos de criação de caráter coletivo num contexto em que os estudantes deveriam trabalhar remotamente. Na impossibilidade de se utilizar jogos de improvisação teatral e outras técnicas de criação coletiva, nas quais se produzem inter-relações físicocorporais performativas, a função de se criar uma costura entre as diferentes performances dos estudantes, realizadas em diferentes espaços, foi transferida para procedimentos digitais de edição e montagem, impondo novos percursos de criação e investigação até então desconhecidos para os professores e para boa parte dos alunos. Como observado nos experimentos práticos desenvolvidos na última disciplina, o estudante que se responsabilizava pelo trabalho de edição acabava por exercer enorme influência sobre o resultado final do experimento, chegando, inclusive, a determinar o sentido global do trabalho. Essa característica "centralizadora" do processo criativo, concentrado nas mãos de uma determinada pessoa e agravada pelo contexto de isolamento social durante a pandemia, significou, em alguns momentos, uma dificuldade a mais a ser contornada do ponto de vista didático-pedagógico. Além disso, alguns experimentos acabaram não se concretizando, como a proposta inicial de se montar uma obra única a partir do acervo de vídeos produzido na primeira disciplina com ações realizadas 
em diferentes banheiros, cozinhas e quartos. Percebe-se, aqui, uma frente que se abre para que possamos experimentar outras metodologias para a construção de experimentações remotas de modo mais coletivo.

Se, por um lado, as experimentações remotas de caráter coletivo representaram um especial desafio, por outro lado, a qualidade alcançada na realização dos trabalhos individuais foi inesperada. Nesse sentido, é preciso destacar o surpreendente domínio dos alunos sobre o uso da câmera e de ferramentas de edição de imagens. A disponibilidade e o acesso a tais ferramentas na rede, de forma gratuita, e o natural envolvimento dos alunos com recursos digitais na sua vivência cotidiana viabilizaram a realização dos experimentos práticos sem que houvesse nenhum tipo de treinamento ou orientação técnica específica neste campo. Além disso, os alunos não dispunham de recursos tecnológicos sofisticados e profissionais, o que nos revelou que, mesmo nesse ambiente mais amador, é possível desenvolver bons trabalhos com o que há disponível. Temos à nossa frente uma geração de alunos totalmente "digitalizada", cujas relações sociais são, em larga medida, construídas nos ambientes virtuais das redes, a exemplo de plataformas como Instagram, Twitter ou Tiktok. A experiência realizada nesse percurso didático-pedagógico nos mostra, portanto, que as habilidades dos alunos com ferramentas digitais e sua vivência no mundo virtual possibilitam ou mesmo induzem novas frentes de ação. Afinal, se vivemos num cotidiano cada vez mais digitalizado e mediado por telas, os experimentos audiovisuais cênico-performáticos realizados no âmbito da web parecem se firmar não apenas como uma linguagem estética, mas como uma importante forma de expressão artística e social. Nesse sentido, acreditamos ser necessário pensar na incorporação desse tipo de experimento como ferramenta pedagógica para além do contexto da pandemia do Covid 1915, entendendo essas práticas audiovisuais da web como importantes manifestações culturais do mundo contemporâneo a serem investigadas e estudadas no âmbito acadêmico.

A escrita desse artigo não se pautou por uma articulação de teorias ou de

${ }^{15}$ Cabe ressaltar que, na reforma curricular do Curso de Graduação em Teatro que está em andamento na UFMG, há a previsão da incorporação de uma disciplina obrigatória que terá como tema a relação entre teatro e tecnologia, com foco nas neotecnologias digitais. 
conceitos, mas pelo desejo do compartilhamento de uma experiência vivenciada no campo didático-pedagógico, acreditando que esse compartilhamento pode contribuir para a construção de metodologias futuras diante das novas perspectivas que se abrem num mundo pós-pandemia.

\section{Referências}

AUMONT, Jacques. As teorias dos cineastas. Campinas: Papirus, 2004.

MARTIN, Marcel. A linguagem cinematográfica. São Paulo: Brasilense, 2003.

DIRETÓRIO dos grupos de pesquisa no Brasil. Barracão: Núcleo de Pesquisa e Experimentação em Cenografia e outras práticas espaciais cênico-performáticas. 2014. Disponível em: <http://dgp.cnpq.br/dgp/espelhogrupo/8430353857049429>. Acesso em: 30 out. 2019.

FEDERICI, Silvia. O ponto zero da revolução: trabalho doméstico, reprodução e a luta feminista. São Paulo: Elefante, 2019.

PEDRON, Denise. A escrita de si e a criação da cena experiência - Domingo. Seminário Internacional Fazendo Gênero 11 \& 13th Women's Worlds Congress (Anais Eletrônicos), Florianópolis, 2017.

Recebido em: 15/06/2021

Aprovado em: 18/08/2021 